\title{
Влияние материала подложки на свойства пленок оксида галлия и структур на его основе
}

\author{
(C) В.М. Калыгина, Т.З. Лыгденова, Ю.С. Петрова, Е.В. Черников \\ Национальный исследовательский Томский государственный университет, \\ 634050 Томск, Россия \\ E-mail: Kalygina@ngs.ru
}

(Получена 1 сентября 2018 г.

Принята к печати 8 октября 2018 г.

Принята к публикации 8 октября 2018 г.)

\begin{abstract}
Изучено влияние материала подложки на свойства пленок оксида галлия, полученных на сапфировых и полупроводниковых пластинах $n(p)$-GaAs методом высокочастотного магнетронного напыления. Пленки, выращенные на диэлектрических подложках, как правило, оказываются высокоомными, $n$-типа проводимости. Рост проводимости в них с повышением температуры обусловлен ионизацией глубоких донорных центров с энергией $(0.98 \pm 0.02)$ эВ ниже дна зоны проводимости. Независимо от типа проводимости полупроводниковых подложек, пленки оксида галлия, выращенные на монокристаллических слоях GaAs, также имеют $n$-тип проводимости. Однако проводимость таких пленок оказывается существенно выше, что объясняется возможной диффузией неконтролируемых примесей из полупроводника в растущий слой оксида галлия. Электрические характеристики структур $\mathrm{Ga}_{2} \mathrm{O}_{3}$-полупроводник в большей степени определяются свойствами границы раздела оксид-полупроводник, чем свойствами контактирующих материалов. На обратной ветви вольт-амперных характеристик образцов $\mathrm{Ga}_{2} \mathrm{O}_{3} / p$-GaAs до отжига наблюдается участок отрицательного сопротивления $\mathrm{N}$-типа. После отжига пленок оксида галлия при $900^{\circ} \mathrm{C}$ (30 мин) проводимость структур соответствует вольт-амперной характеристике обращенного диода.
\end{abstract}

DOI: 10.21883/FTP.2019.04.47442.8990

\section{1. Введение}

При изготовлении монокристаллов и пленок оксида галлия разными методами в запрещенной зоне $\mathrm{Ga}_{2} \mathrm{O}_{3}$ возникает спектр дефектных состояний, различающихся концентрацией и энергетическим положением. Согласно опубликованным данным [1-3], наиболее часто определяемым дефектным уровням соответствуют значения энергий $0.62,0.82,1.00,2.16$ и 4.40 эВ при отсчете от дна зоны проводимости $E_{c}$. Как правило, они обусловлены вакансиями атомов кислорода или галлия, антиструктурными дефектами, атомами в междоузлиях, случайными примесями и т.д.

Уровни $E_{c}-0.82$ эВ и $E_{c}-4.40$ эВ являются доминирующими, с концентрациями $\sim 10^{16} \mathrm{~cm}^{-3}$. Три типа ловушек, с энергиями $0.62,0.82$ и 1.00 эВ, обнаруживаются методом DLTS (deep level transient spectroscopy), они аналогичны ловушкам, зарегистрированным в монокристаллах $\beta-\mathrm{Ga}_{2} \mathrm{O}_{3}$, выращенных методом Чохральского. Для обнаруженных DLTS состояний при $E_{c}-2.16$ эВ и $E_{c}-4.40$ эВ характерны значительные релаксационные эффекты [1].

Электрические и оптические свойства структур, изготовленных на основе монокристаллов и пленок оксида галлия, помимо всего прочего определяются поведением дефектов в электрических полях, при изменении температуры и при воздействии излучений с разной длиной волны. Особую роль могут играть примеси, как специально введенные в $\mathrm{Ga}_{2} \mathrm{O}_{3}$ с целью получения материала с заданными характеристиками, так и неконтролируемые, которые оказываются в образцах в процессе выращивания либо при последующих технологических обработках.

В данной работе исследовалось влияние материала подложки на свойства пленок оксида галлия, полученных на сапфировых и полупроводниковых пластинах $n(p)$-GaAs методом высокочастотного магнетронного напыления.

\section{2. Методика эксперимента}

Пленки оксида галлия толщиной 150-200 нм наносили высокочастотным (ВЧ) магнетронным напылением на сапфировые или полупроводниковые подложки $n$ или $p$-GaAs. Напыление оксида галлия проводилось на ненагретые подложки распылением мишени $\mathrm{Ga}_{2} \mathrm{O}_{3}$ $(99.9999 \%)$ в газовой смеси $\mathrm{Ar} / \mathrm{O}_{2}$ на установке AUTO500 (производитель Edwards). Концентрация кислорода в смеси поддерживалась равной $(56.1 \pm 0.5)$ об\%. Расстояние между мишенью и подложкой составляло 70 мм. Давление в камере во время напыления поддерживалось равным $7 \cdot 10^{-3}$ бар.

Перед нанесением оксидной пленки на сапфировые подложки последние подвергались химической очистке с последующим формированием с помощью фотолитографии платиновых электродов и нагревателя для проведения температурных измерений вольт-амперных характеристик (BAX) полученных образцов. Вид планарной структуры на сапфировой подложке приведен на рис. $1, a$.

При изготовлении образцов на полупроводниковых подложках пленки оксида галлия наносили на нена- 

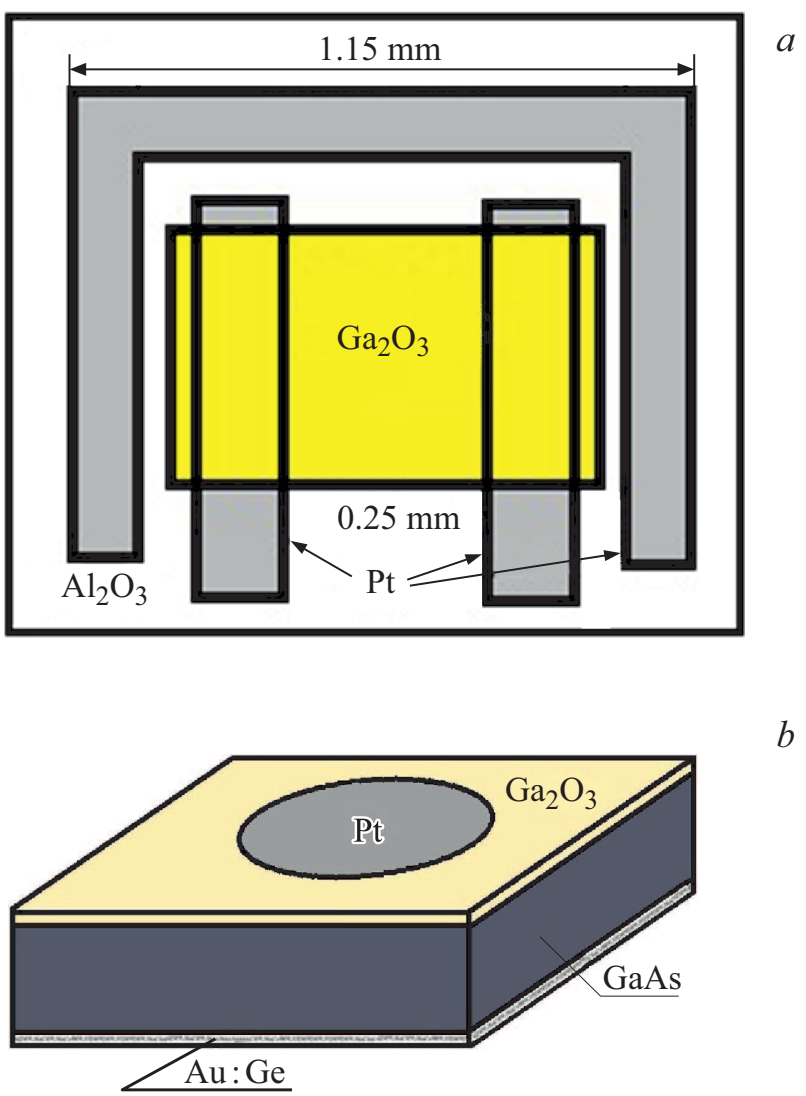

Рис. 1. Схематическое изображение образцов на сапфировой $(a)$ и полупроводниковой $(b)$ подложках.

гретые пластины $n$-GaAs или p-GaAs. Концентрация основных носителей заряда в обоих полупроводниках составляла $1 \cdot 10^{18} \mathrm{~cm}^{-3}$. Перед нанесением диэлектрика подложки подвергали стандартной химической обработке, в процессе которой происходило удаление различных загрязнений и естественного оксида. После получения оксидной пленки проводилось напыление Pt-электродов на поверхность $\mathrm{Ga}_{2} \mathrm{O}_{3}$ через маски диаметром 1.15 мм. Площадь металлического контакта к пленке оксида галлия составляла $S_{c}=1.04 \cdot 10^{-2} \mathrm{~cm}^{2}$. На тыльную сторону пластины GaAs наносили сплошной металлический контакт (сандвич-структуры). По завершении всех процессов напыления полупроводниковые подложки с полученными структурами разрезали на отдельные чипы размером $1.7 \times 1.7 \mathrm{Mм}$ (рис. $1, b)$.

Вольт-амперные характеристики в интервале температур $T=293-363 \mathrm{~K}$ исследовали с помощью измерителя Keithley 2611В при использовании термостата, позволяющего поддерживать температуру с точностью $0.1 \mathrm{~K}$.

\section{3. Результаты и их обсуждение}

Планарные образцы на сапфировых подложках обладают высоким сопротивлением при $290 \mathrm{~K}$. Вольтамерные характеристики представляют собой линейную зависимость тока $I$ от напряжения $U$ в интервале электрических полей $1-10^{4} \mathrm{~B} / \mathrm{cm}$. На рис. 2 показано характерное поведение ВАХ таких образцов при изменении температуры в интервале $293-363 \mathrm{~K}$.

C повышением температуры проводимость пленок растет по экспоненциальному закону с энергией активации $\Delta E_{t}=(0.98 \pm 0.02)$ эВ (рис. 3). С учетом ширины запрещенной зоны $\mathrm{Ga}_{2} \mathrm{O}_{3}\left(E_{g}=4.84-4.9\right.$ эВ) и данных рис. 2 следует предположить, что рост проводимости пленок с повышением температуры обусловлен ионизацией глубоких донорных центров, расположенных на 0.98 эВ ниже дна зоны проводимости. Полученное значение энергии активации с точностью до погрешности эксперимента совпадает с данными для глубоких доноров, модель которых предложена в работе [2] (энергия $\Delta E_{d}=1$ эВ). Отжиг в аргоне при $900^{\circ} \mathrm{C}$ в течение 30 мин пленок оксида галлия, полученных на сапфировых подложках, не приводил к каким-либо заметным изменениям их электрических характеристик.

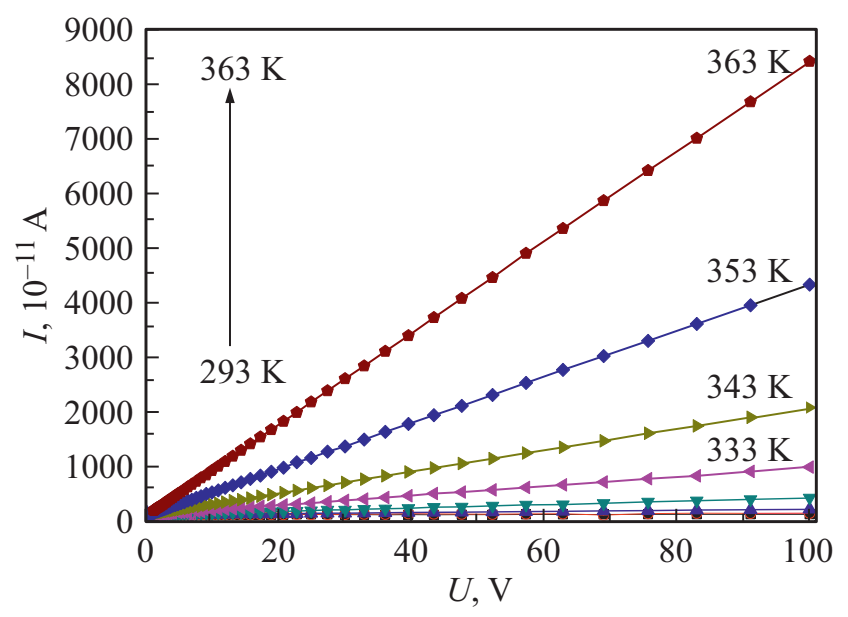

Рис. 2. Температурная зависимость вольт-амперных характеристик образца на сапфировой подложке.

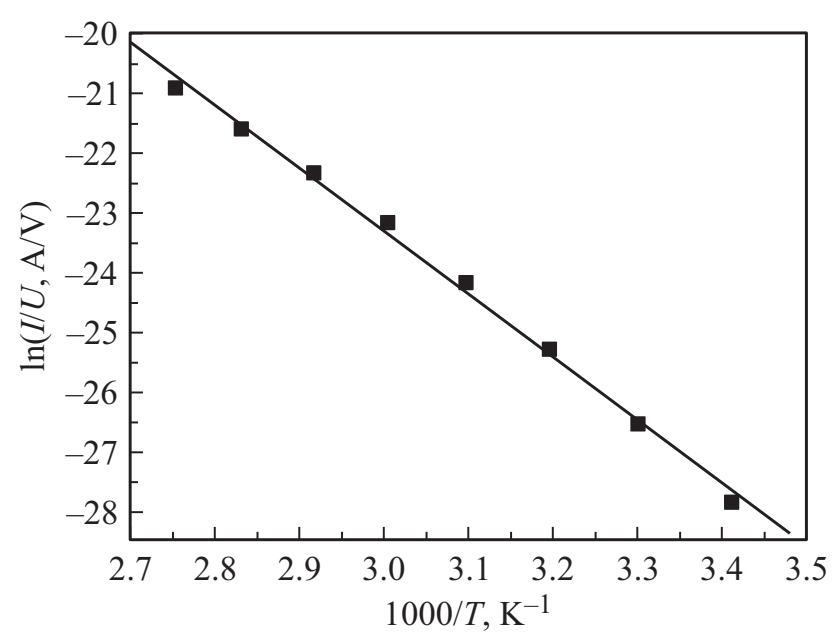

Рис. 3. Температурная зависимость проводимости оксидной пленки на сапфировой подложке. 

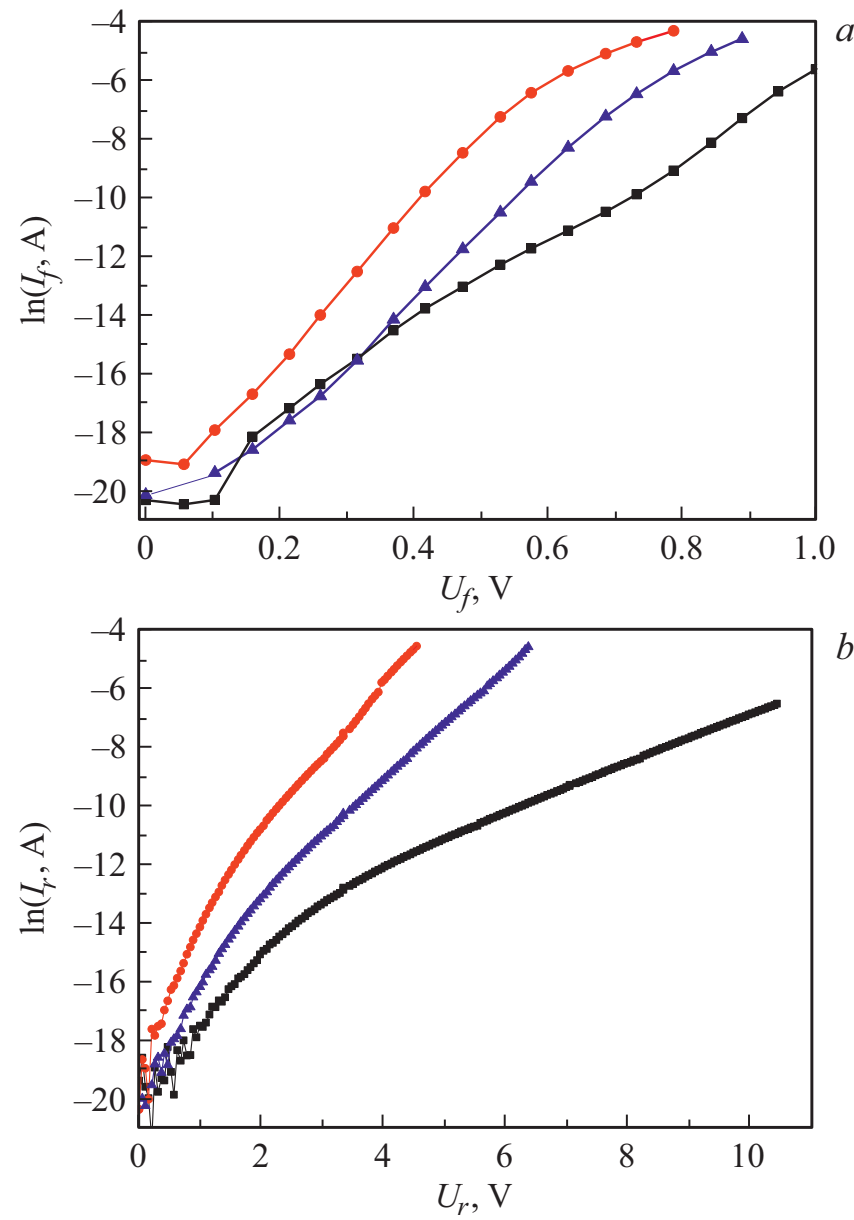

Рис. 4. Прямые $I_{f}\left(U_{f}\right)$ (a) и обратные $I_{r}\left(U_{r}\right)$ (b) BAX нескольких структур $\mathrm{Ga}_{2} \mathrm{O}_{3} / n$-GaAs при $290 \mathrm{~K}$.

Для образцов, полученных на $n$-GaAs, зависимости емкости и проводимости от напряжения имели вид кривых, характерных для изотипных $n$-гетероструктур: емкость и проводимость снижались с повышением положительного и отрицательного напряжения на структуре.

Характерный вид зависимостей тока от напряжения при положительных и отрицательных потенциалах на затворе (электрод к диэлектрику) для структур $\mathrm{Ga}_{2} \mathrm{O}_{3} / n$-GaAs при температуре $T=290 \mathrm{~K}$ показан на рис. 4. Прямым ВАХ соответствуют положительные потенциалы на затворе, а обратным - отрицательные.

Анализ полученных данных показал, что вид прямых BAX и рост тока с повышением температуры определяются инжекцией электронов из $n$-GaAs в пленку диэлектрика. Зависимость плотности тока от напряжения описывается соотношением [4]

$$
I=A^{*} T^{2} \exp \left(-\frac{e \Phi_{b}}{k T}\right) \exp \left(\frac{e \sqrt{e \mathscr{E} / 4 \pi \varepsilon_{s} \varepsilon_{0}}}{k T}\right),
$$

где $A^{*}$ - постоянная Ричардсона, $\mathscr{E}-$ напряженность электрического поля, $k$ - постоянная Больцмана, $e-$ заряд электрона, $\varepsilon_{s}$ - диэлектрическая проницаемость полупроводника, $\varepsilon_{0}$ - электрическая постоянная, $\Phi_{b}-$

\begin{tabular}{c|c}
\hline Номер образца & $\Phi_{b}$, эВ \\
\hline 4 & $0.64 \pm 0.06$ \\
3 & $0.73 \pm 0.07$ \\
2 & $0.42 \pm 0.05$ \\
5 & $0.86 \pm 0.10$
\end{tabular}

высота потенциального барьера. На рис. 5, $a$ приведены прямые вольт-амперные характеристики в координатах Шоттки для одного из образцов $\mathrm{Ga}_{2} \mathrm{O}_{3} / n$-GaAs в интервале температур 285-363 K.

Используя соотношение (1) и полученные экспериментальные кривые, определили высоту потенциального барьера на границе $\mathrm{Ga}_{2} \mathrm{O}_{3} / n-\mathrm{GaAs}$ (см. таблицу). Средняя высота потенциального барьера составляет $(0.66 \pm 0.02)$ эВ.

При отрицательных потенциалах на затворе напряжение падает в основном на области пространственного заряда в GaAs. Если учесть большие значения концентрации электронов в $n$-GaAs $\left(10^{18} \mathrm{~cm}^{-3}\right)$, барьер должен быть достаточно узким.
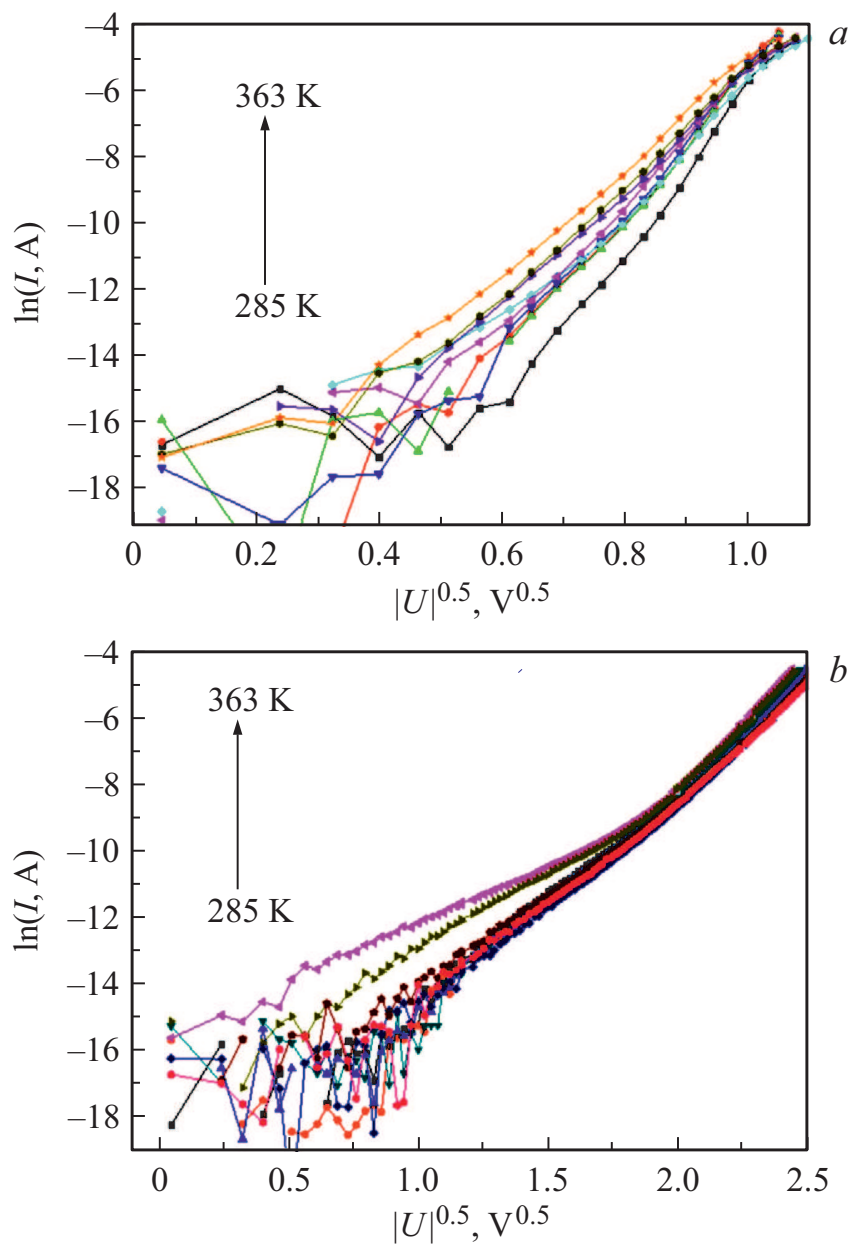

Рис. 5. Температурная зависимость вольт-амперных характеристик при положительных $(a)$ и отрицательных $(b)$ потенциалах на затворе. 


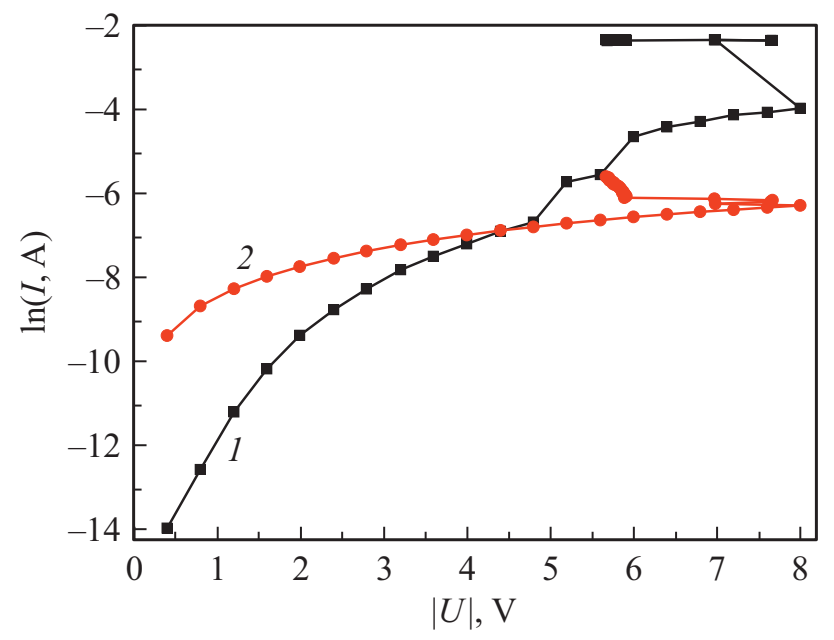

Рис. 6. Прямая (1) и обратная (2) ВАХ образца $\mathrm{Ga}_{2} \mathrm{O}_{3} / n$-GaAs после отжига в аргоне при $900^{\circ} \mathrm{C}$.

Как видно из рис. 5, $b$, влияние температуры на токи через образец наблюдается только в интервале слабых и средних электрических полей. Характер температурной зависимости ВАX $I(U)$ и спрямление данных в координатах $\ln I \propto U^{0.5}$ позволяет предположить эмиссию электронов из диэлектрика в полупроводник.

C повышением напряжения изменение тока с температурой ослабевает, и в области сильных электрических полей вольт-амперные характеристики образцов становятся неразличимыми. Этот факт позволяет предположить, что в области сильных электрических полей преобладает туннелирование электронов через вершину потенциального барьера (рис. 5, $b$ ).

После отжига структур $\mathrm{Ga}_{2} \mathrm{O}_{3} / n$-GaAs в аргоне при $900^{\circ} \mathrm{C}$ в течение 30 мин ВАХ претерпевают заметные изменения. На рис. 6 показан характерный вид прямой и обратной ветвей одного из образцов $\mathrm{Ga}_{2} \mathrm{O}_{3} / n$-GaAs после отжига. Особенностью BAX таких образцов является наличие участка с отрицательным дифференциальным сопротивлением $S$-типа при положительных и отрицательных потенциалах на затворе. Кроме того, в области малых напряжений прямые токи на несколько порядков ниже обратных.

Сравнивая характеристики структур на сапфировой и полупроводниковой подложках, следует отметить более высокую проводимость образцов, полученных на GaAs. Большие значения токов в сандвич-структурах объясняются диффузией примесей из полупроводника в оксид галлия в процессе роста пленки. Изменения BAX после высокотемпературного отжига вызваны как структурно-фазовыми превращениями в $\mathrm{Ga}_{2} \mathrm{O}_{3}$ [5], так и более интенсивной диффузией примесей из подложки в оксидную пленку при $900^{\circ} \mathrm{C}$.

На рис. 7 показаны вольт-амперные характеристики структур $\mathrm{Ga}_{2} \mathrm{O}_{3} / p$-GaAs без отжига при высокой температуре при положительных и отрицательных потенциалах на затворе. Концентрация дырок в $p$-GaAs, как отмечено выше, составляла $1 \cdot 10^{18} \mathrm{~cm}^{-3}$. Из представленных кривых следует, что при положительных напряжениях в интервале $0 \leq U \leq 5 \mathrm{~B}$ ток $I$ растет с напряжением по линейному закону, и при $U \geq 6 \mathrm{~B}$ наблюдается резкий рост $I$.

На обратной ветви ВАХ имеется участок отрицательного дифференциального сопротивления $N$-типа, который для всех исследованных образцов начинается при напряжениях 2-4B. Проводимость таких образцов с учетом высокой концентрации дырок в $p$-GaAs и большой концентрации электронов в $\mathrm{Ga}_{2} \mathrm{O}_{3}\left(10^{17}-10^{18} \mathrm{~cm}^{-3}\right)$ объясняется туннельными переходами электронов из GaAs в оксидную пленку. Электроны туннелируют на свободные места в зоне проводимости $\mathrm{Ga}_{2} \mathrm{O}_{3}$, и на BAX наблюдается участок отрицательного сопротивления $N$-типа.

При положительных потенциалах на затворе имеет место инжекция электронов из металлического контакта

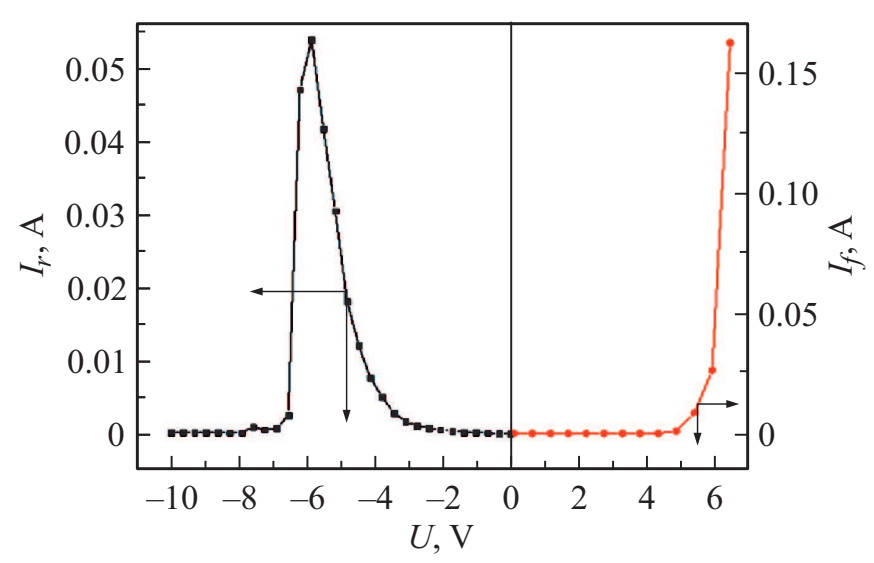

Рис. 7. Вольт-амперные характеристики структур $\mathrm{Ga}_{2} \mathrm{O}_{3} / p$-GaAs без отжига при высокой температуре и при положительных, отрицательных потенциалах на затворе.

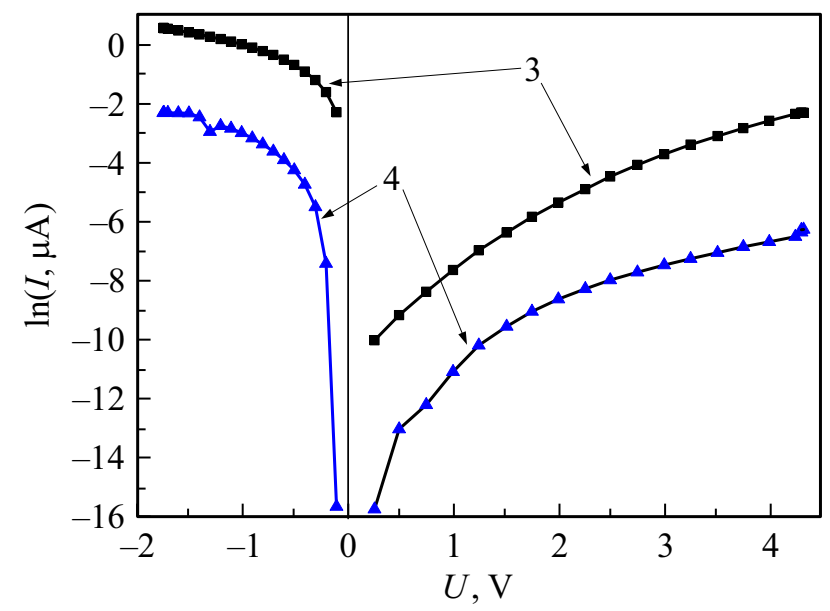

Рис. 8. Вольт-амперные характеристики структуры $\mathrm{Ga}_{2} \mathrm{O}_{3} / p$-GaAs (образцы 3,4) после отжига в $\mathrm{Ar}$ при $900^{\circ} \mathrm{C}$ (30 мин) при положительных и отрицательных потенциалах на затворе. 


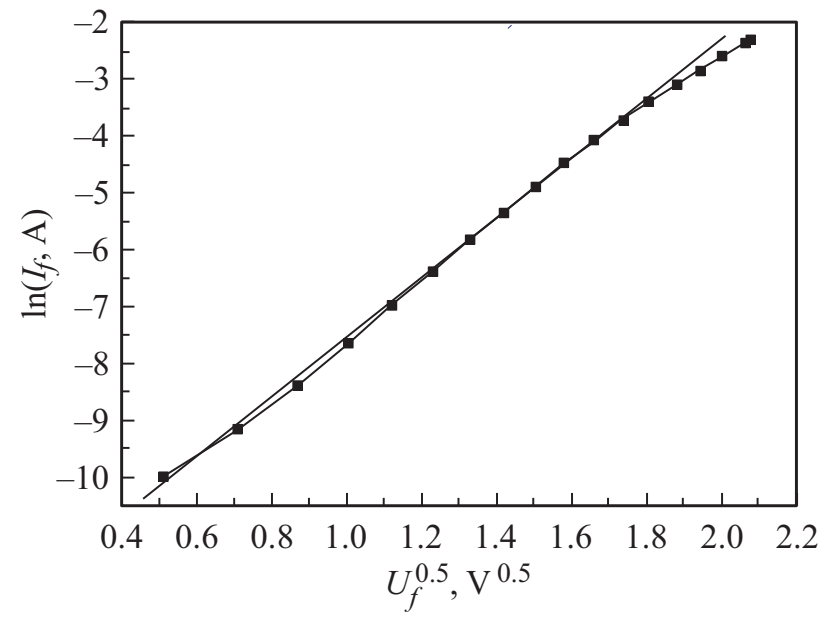

Pис. 9. Прямая ветвь $\mathrm{BAX}$ структуры $\mathrm{Ga}_{2} \mathrm{O}_{3} / p$-GaAs после отжига в $\mathrm{Ar}$ при $900^{\circ} \mathrm{C}(30$ мин).

в оксидную пленку. Ток слабо растет с повышением напряжения до $U=5-6 \mathrm{~B}$ и резко увеличивается при дальнейшем повышении $U$.

Отжиг структур $\mathrm{Ga}_{2} \mathrm{O}_{3} / p$-GaAs в $\mathrm{Ar}$ при $900^{\circ} \mathrm{C}$ (30 мин) приводит к резким изменениям BAX (рис. 8). Предполагается, что это связано с увеличением концентрации электронов $n_{0}$ в оксиде галлия. Рост $n_{0}$ в $\mathrm{Ga}_{2} \mathrm{O}_{3}$ происходит за счет диффузии примеси из арсенида галлия во время отжига пленок при высокой температуре. Полученные зависимости соответствуют вольтамперным характеристикам обращенного диода (высокая проводимость при обратных смещениях и малая при прямых).

При прямых смещениях электроны из затвора инжектируются в оксид галлия, и прямая ВАХ определяется соотношением $\ln I_{f} \propto U_{f}^{0.5}$ (рис. 9).

При отрицательных потенциалах электроны из GaAs переходят на свободные места в зоне проводимости $\mathrm{Ga}_{2} \mathrm{O}_{3}$, частично заполненной электронами. В интервале малых отрицательных смещений зависимость тока от напряжения может быть представлена формулой

$$
I \approx B_{1} \exp \left(\frac{|U|}{B_{2}}\right),
$$

где $B_{1}$ и $B_{2}-$ положительные величины, слабо зависящие от напряжения [6].

\section{4. Заключение}

Анализируя вышеизложенные данные, приходим к выводу, что при использовании одного и того же метода нанесения пленок оксида галлия и одинакового материала электрода к $\mathrm{Ga}_{2} \mathrm{O}_{3}(\mathrm{Pt})$ свойства исследованных структур зависят от материала подложки и последующих технологических обработок. Электрофизические характеристики материала подложки (теплопроводность, тип проводимости, концентрация носителей заряда и т. д.) оказывают определяющее влияние на формирование структуры, фазового состава, размеры зерен (если пленка поликристаллическая), их кристаллографическую ориентацию, структуру дефектов. Из наших данных следует, что пленки, выращенные на диэлектрических подложках, как правило, оказываются высокоомными, $n$-типа проводимости. Рост проводимости в них с повышением температуры обусловлен ионизацией глубоких донорных центров с энергией $(0.98 \pm 0.02)$ эВ ниже дна зоны проводимости. Природа этих донорных уровней не анализируется.

Независимо от типа проводимости полупроводниковых подложек, пленки оксида галлия, выращенные на монокристаллических слоях GaAs, также имеют проводимость $n$-типа. Однако проводимость таких пленок оказывается существенно выше, что объясняется возможной диффузией неконтролируемых примесей из полупроводника в растущую пленку. Электрические характеристики структур $\mathrm{Ga}_{2} \mathrm{O}_{3}$-полупроводник в большей степени определяются свойствами границы раздела оксид-полупроводник, чем свойствами контактируемых материалов.

Отжиг в инертной среде при высокой температуре оказывает существенное влияние на структуру и электрофизические характеристики напыленных слоев оксида галлия. Экспериментальные результаты, полученные в данной работе, не противоречат ранее опубликованным в цитируемой литературе и позволяют сделать следующие выводы.

- Пленки оксида галлия, нанесенные на сапфировые и полупроводниковые подложки, оказываются поликристаллическими и содержат кристаллиты $\alpha$ - и $\beta$-фазы. После отжига в $\mathrm{Ar}$ пленки переходят в $\beta$-фазу.

- Вольт-амперные характеристики образцов планарной конструкции (сапфировые подложки) представляют собой линейную зависимость тока от напряжения. Энергия активации роста проводимости в интервале $20-90^{\circ} \mathrm{C}$ составляет $(0.98 \pm 0.02)$ эВ.

- Проводимость структур $\mathrm{Ga}_{2} \mathrm{O}_{3} / n$-GaAs при положительных и отрицательных потенциалах на затворе определяется эффектом Шоттки. Средняя высота потенциального барьера составляет $(0.66 \pm 0.02)$ эВ.

- На обратной ветви вольт-амперных характеристик образцов $\mathrm{Ga}_{2} \mathrm{O}_{3} / p$-GaAs до отжига наблюдается участок отрицательного сопротивления $N$-типа. После отжига пленок оксида галлия при $900^{\circ} \mathrm{C}$ проводимость структур соответствует ВАХ обращенного диода.

\section{Список литературы}

[1] Z. Zhang, E. Farzana, A. Arehart, S.A. Ringel. Appl. Phys. Lett., 108, 052105 (2016).

[2] J. B. Varley, J.R. Weber, A. Janotti, C.G. Van de Walle. Appl. Phys. Lett., 97, 142106 (2010).

[3] E.G. Vilora, K. Shimamura, Y. Yoshikawa, T. Ujiie, K. Aoki. Appl. Phys. Lett., 92, 202120 (2008).

[4] F.-C. Chiu. Adv. Mater. Sci. Eng., v. 2014. Article ID 578168 (2014). 
[5] В.М. Калыгина, Т.З. Лыгденова, В.А. Новиков, Ю.С. Петрова, А.В. Цымбалов, Т.М. Яскевич. ФТП, 53 (3), 411 (2019).

[6] С. Зи. Физика полупроводников (М., Мир, 1984) т. 2.

Редактор Л.В. Шаронова

\section{Influence of substrate material on \\ properties of gallium oxide films and structures based on it}

V.M. Kalygina, T.Z. Lygdenova, Yu.S. Petrova, E.V. Chernikov

National Research Tomsk State University, 634050 Tomsk, Russia

Abstract The influence of a substrate material on properties of gallium oxide films obtained by $\mathrm{HF}$ magnetron sputtering on sapphire and $n(p)$-GaAs semiconductor substrates is studied. The films grown on the dielectric substrates tend to be high-resistance, of $n$-type conductivity. The increase of conductivity in them with increasing temperature is due to ionization of deep donor centers with the energy $(0.98 \pm 0.02) \mathrm{eV}$ below the bottom of the conduction band. Regardless of the conductivity type of semiconductor substrates, gallium oxide films grown on singlecrystal GaAs layers are also of $n$-type conductivity. However, the conductivity of such films is much higher, what is explained by the possible diffusion of unintentional impurities from the semiconductor into the growing film. The electrical characteristics of the $\mathrm{Ga}_{2} \mathrm{O}_{3}$-semiconductor structures are determined to a greater degree by properties of the oxide-semiconductor interface than by properties of the contacting materials. On the reverse branch of the current-voltage characteristics of $\mathrm{Ga}_{2} \mathrm{O}_{3} / p$-GaAs samples before annealing, a section of negative $N$-type resistance is observed. After annealing the gallium oxide films at $900^{\circ} \mathrm{C}(30 \mathrm{~min})$, the conductivity of the structures corresponds to the current-voltage characteristic of a backward diode. 